\title{
THE EFFECTS ON RENAL RESISTANCE TO BLOOD FLOW OF RENIN, ANGIOTONIN, PITRESSIN AND ATROPINE, HYPERTENSION, AND TOXEMIA OF PREGNANCY1
}

\author{
BY HAROLD LAMPORT \\ (From the Department of Neurology, College of Physicians and Surgeons, Columbia University, \\ and The Neurological Institute, New York City)
}

(Received for publication May 8, 1942)

The interpretation of the observations on the clearances of inulin and diodrast, as measures of rate of glomerular filtration and of renal plasma flow, has been handicapped by lack of quantitative criteria of changes in afferent and efferent renal arteriolar resistance. Most of the qualitative criteria suffer because they do not take account of simultaneous changes in blood pressure, and because they over-simplify by ascribing the effect either to the afferent or the efferent arterioles alone. Where so many factors are interrelated, as in the components determining renal arteriolar resistance, mathematical relationships are necessary. We have previously offered formulas for renal arteriolar resistance $(1,2)$. They have here been applied to data on renal function in dogs, and also in man, published by Corcoran and Page et al. (3 to 7), whom we wish to thank for their kindness in putting at our disposal supplemental and unreported observations. $^{3}$ We are also grateful to Mr. Julius Stein for his painstaking aid in computation.

\section{METHOD}

The formulas for afferent and efferent renal arteriolar resistance are respectively:

$$
\begin{aligned}
& R_{A}=\frac{P_{M}-P_{O^{\prime}}-40}{H D} ; \\
& R_{E}=\frac{(1-0.47 F)\left(P_{O}^{\prime}-P_{O}+10\right)}{H D} ; \\
& P_{O^{\prime}}=\frac{2.34 S}{1-0.0542 S-F} .
\end{aligned}
$$

1 Presented in part at the March, 1942, meeting of the American Physiological Society.

2 Now at the Department of Physiology, Yale University School of Medicine, New Haven.

The supplemental data were the hematocrit values which are here supplied in full in the form of $1 /(1$-hematocrit) $=H$. All unreported cases are indicated as such in the tables, where all the data for calculation are supplied. We are assured by the authors that the technique and conditions of the unreported cases were the same as those already reported, with which they are included.
Here $P_{M}$ is the mean of systolic and diastolic blood pressure; $P_{O}$ is the osmotic pressure of the systemic blood $(F=0)$, while $P_{o}^{\prime}$ is the osmotic pressure of the blood after a fraction, $F$, of the plasma has been filtered off in the glomerulus. These pressures are measured in millimeters of mercury. $D$ is the diodrast clearance or effective renal plasma flow in cc. per minute per individual, or per unit surface area. No allowance is made for discrepancy between $D$ and effective plasma flow. $I$ is the inulin clearance in the same units as $D . \quad F=I / D . \quad S$ is the concentration of serum protein in grams per $100 \mathrm{cc}$. No correction for $A: G$ ratios differing from our standard of 2.20 has been applied, but means for such adjustment are available where the ratios are known (2). $H$ is the reciprocal of 1-hematocrit, expressed as a fraction of 1 , and $H D$ is therefore effective renal blood flow. Since Corcoran and Page in their animal experiments found the rate of renal blood flow in the exteriorized kidney by the Fick principle, analyzing arterial and renal venous blood directly for both phenol red and inulin, we use the average of their plasma flow values derived from these two substances for our $D$. $P_{G}$, glomerular intra-capillary pressure, is given by the approximation, $P_{o^{\prime}}+20$ (1).

The sum of arteriolar resistance is $R=R_{A}+R_{B}$. Being resistances, each of these symbols is properly expressed in terms of the units of the formulas: millimeters of mercury per cc. individual's own blood per minute per individual, or per unit surface area. In all cases, except those with toxemia of pregnancy, the resistance is referred to the individual's own blood as standard perfusing medium, so that the resistance values for one individual are not quite comparable with those of another.

In many of the experiments reported, there is more than one control or experimental period. Strictly speaking, the resistance of the afferent and efferent arterioles for each observation should be calculated separately, and averaging of the whole set of final resistances should be done. However, in a trial series, we studied this method as compared to averaging the individual quantities from which a single resistance is drawn and found no statistically significant difference. Consequently, we have adopted this simpler method of computation, except in a few instances where wide variability within the periods to be averaged suggested individual calculations. For the sake of completeness, we restate the results of Corcoran and Page for blood pressure, renal blood flow, and glomerular filtration rate; the values for glomerular intra-capillary pressure and for arteriolar resistance and its related quantities are original. 
The precision of measurement of renal arteriolar resistance is touched on elsewhere $(1,2)$. It is, of course, clear that results drawn from a formula depend on the accuracy of the data applied. The measurements of clearance are subject to an error estimated at about 10 per cent. In evaluating results, the quality and mass of the data must be considered. We shall not report conclusive changes in numerical quantities, since here this does not seem warranted. However, while it may be incorrect to say, for example, that a 42 per cent increase in a particular quantity was noted, it may be statistically legitimate to report in such an instance simply that an increase occurred.

\section{RESULTS}

\section{Effect of pitressin}

Eight experiments were performed on unanesthetized dogs after the initial results of pitressin had worn off (3). No consistent change in glomerular intra-capillary pressure occurred, nor do changes appear correlated to the degree of blood pressure shift, which is mainly that of slight, usually inconsequential, increase. Total renal arteriolar resistance, while it changed considerably, was not consistent in direction. There is also no consistent change in the ratio of afferent to efferent arteriolar resistance; half of the cases showed an increase and the other half a decrease. The suggestion that constriction of the efferent arterioles occurs during periods of reduced renal blood flow is not supported by the calculations. No particular anatomical site of action or functional effect of pitressin is revealed (Table I).

\section{Effect of atropine after pitressin}

While the addition of intravenous atropine to pitressin, as previously reported (3), did not consistently affect renal blood flow, blood pressure was markedly elevated, and glomerular filtration rate was increased. Despite the marked blood pressure increase, glomerular capillary pressure rose considerably in only 2 of the 5 cases, out of a total of 7 , in which an increase was recorded, and in these 2 cases the blood pressure shift was minor. Statistical analysis reveals that the increase is not significant (23 per cent likelihood of chance alone being responsible). In all cases, total arteriolar resistance rose, with afferent arteriolar constriction predominating in all but 1 case. In fact, the efferent arterioles dilated in 4 of the 7 cases (Table I).

\section{Effect of renin}

Aside from the increase in blood pressure, and fall in renal blood flow (3), renin consistently increased renal arteriolar resistance but, while the increase was predominantly afferent 6 times, it was mainly efferent in origin 8 times. There was a fairly consistent rise in glomerular intracapillary pressure, and an inconsistent tendency to fall in glomerular filtration rate (Table II).

\section{Effect of angiotonin in dogs}

We are indebted to Corcoran and Page for permitting the use of their published experiments with angiotonin (4), and for supplying data supplemental to these published reports. From them have been selected those cases in which calculation showed the glomerular intracapillary pressure to be less than blood pressure. It is possible that our formula for glomerular intracapillary pressure, which depends on the Adairs' and Greaves' observations on osmotic pressure of diluted serum (8), is incorrect at high degrees of hemoconcentration. There are technical difficulties, too, in the measurement of renal blood flow and inulin clearance during the rapid fluctuations produced by angiotonin. For these reasons, as well as the possibility that the formulas may not apply at very high degrees of vasoconstriction (2), the results for angiotonin are subject to doubt. Their similarity to those obtained with renin suggests, however, that they are probably not too unreliable for a first estimate of the effect on renal resistance of angiotonin, particularly in view of the current interest in this drug and the, as yet, unsupported opinions of its mode of activity.

Renal blood flow fell, blood pressure rose, and renal resistance increased markedly during angiotonin infusion in the cases selected as noted. The increased resistance cannot here be ascribed primarily to afferent or efferent arteriolar constriction. On the whole, glomerular intra-capillary pressure rose. Changes in glomerular filtration rate were not consistent (Table III).

\section{Effect of angiotonin in man}

Figure 1 shows the previously reported results of angiotonin infusion in a single human subject (5). The calculations of total arteriolar resist- 
EFFECTS ON RENAL RESISTANCE TO BLOOD FLOW

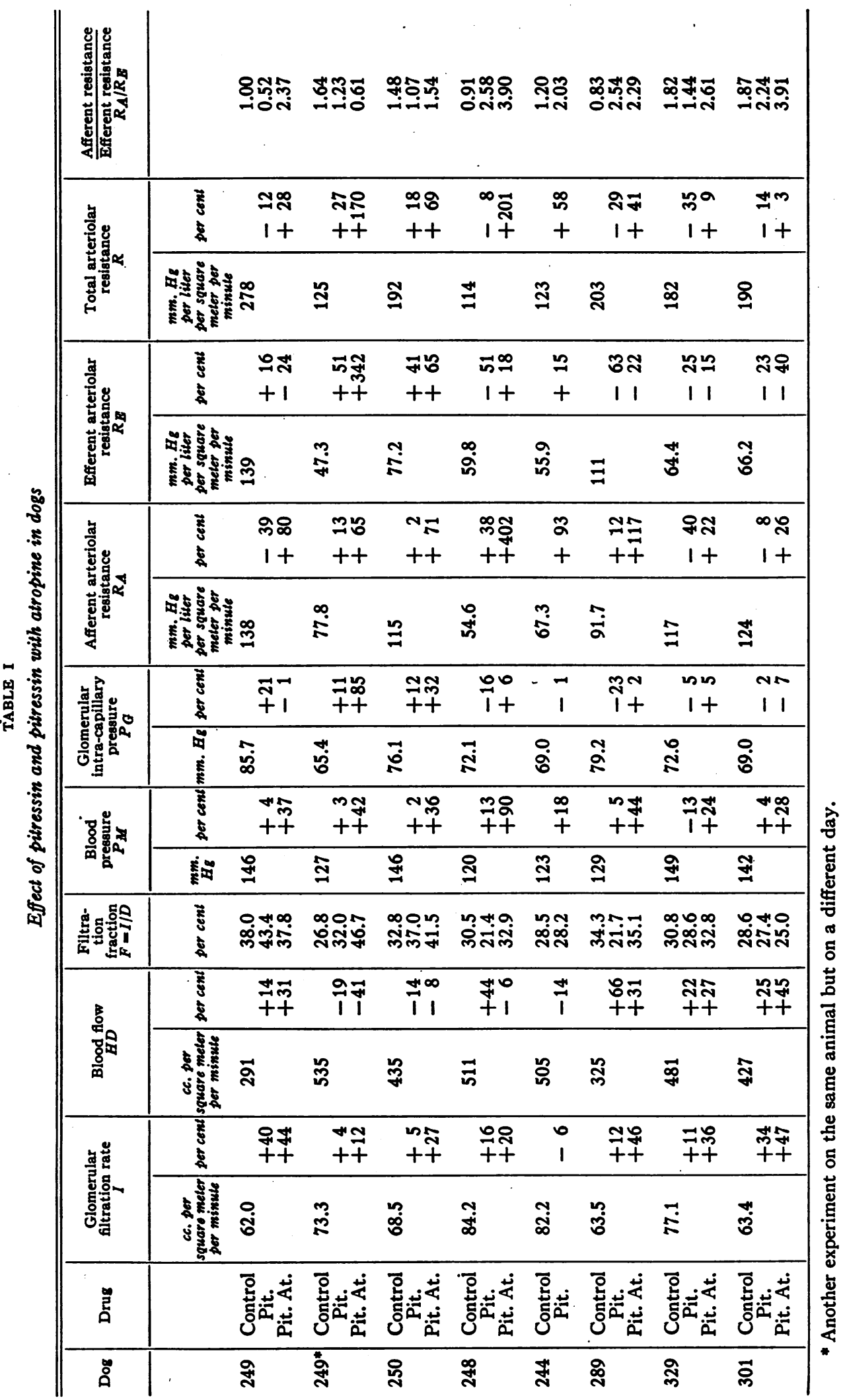




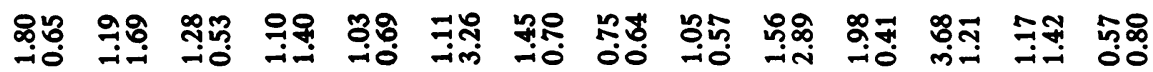

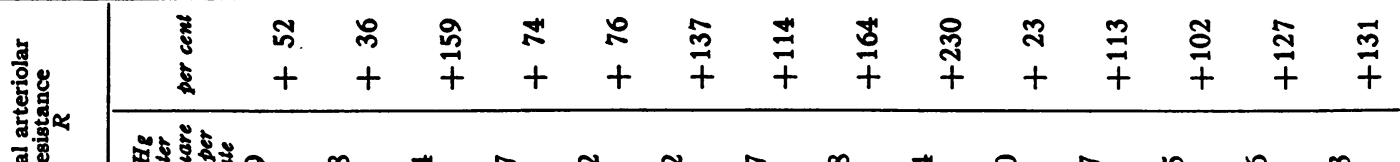

正

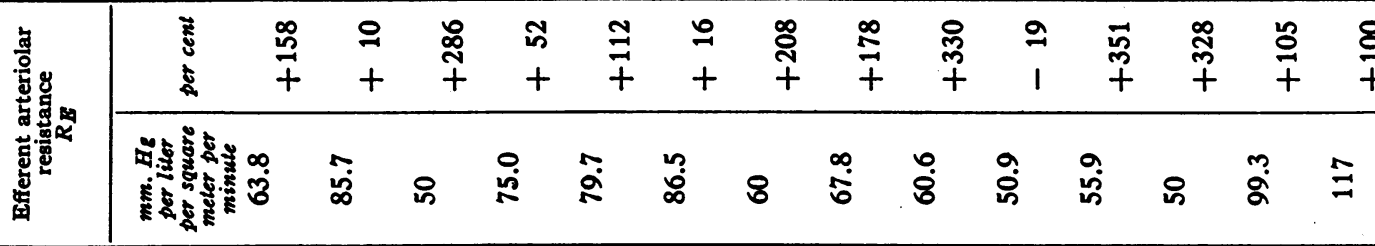

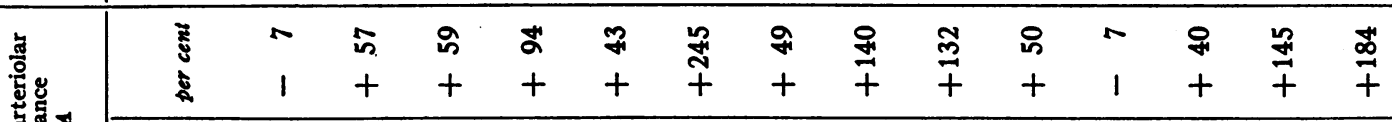

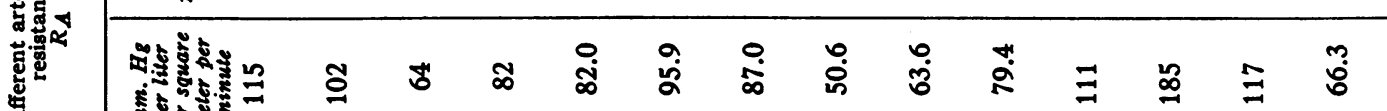

茛

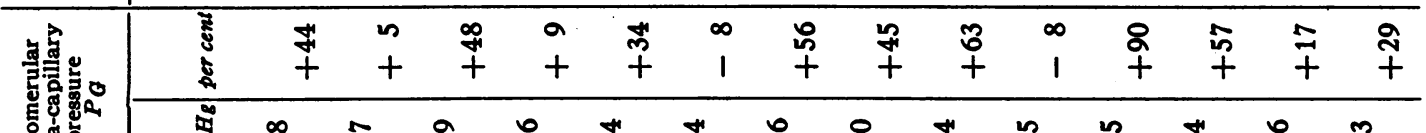
उั.

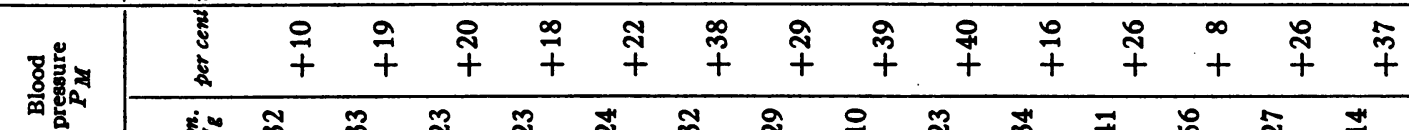

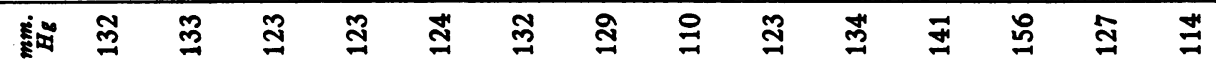

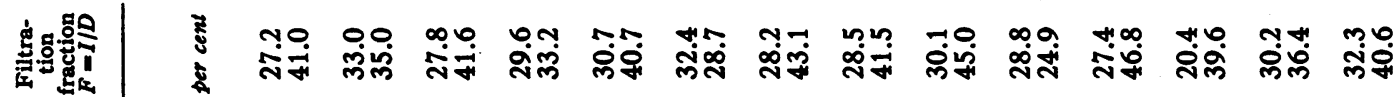

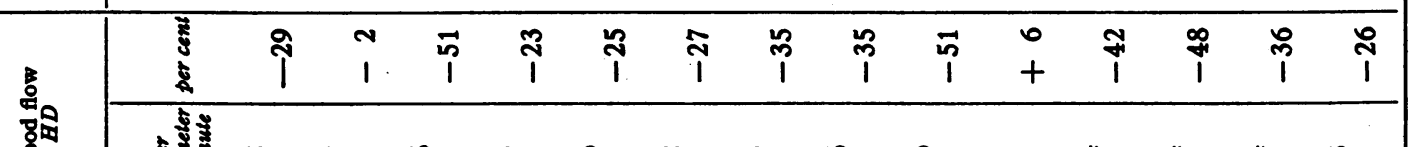

兽

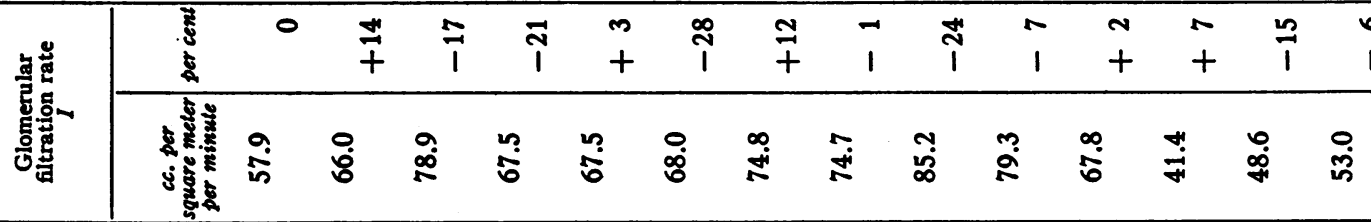

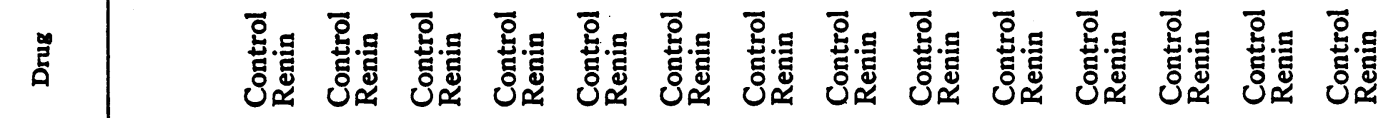

ฉั 
EFFECTS ON RENAL RESISTANCE TO BLOOD FLOW

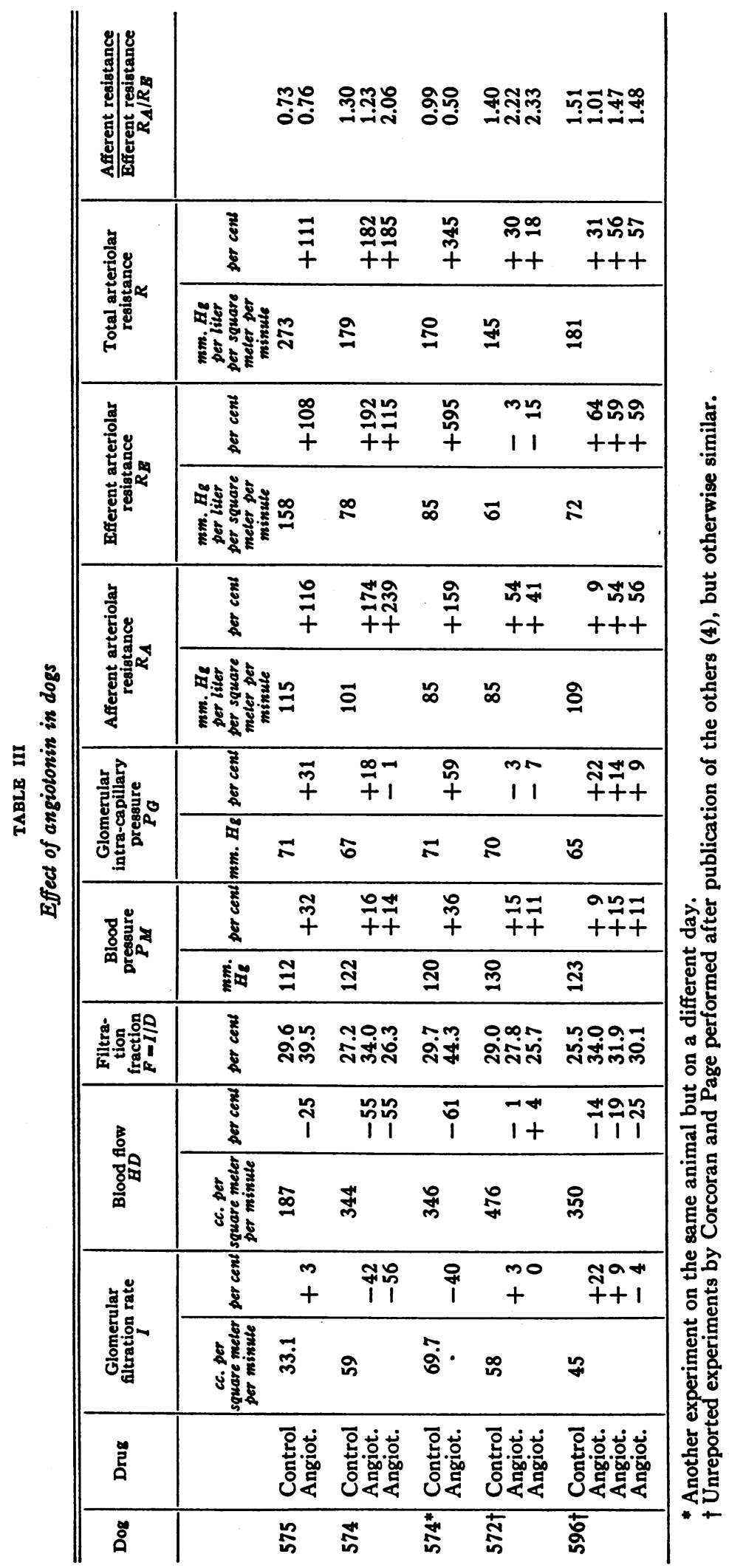




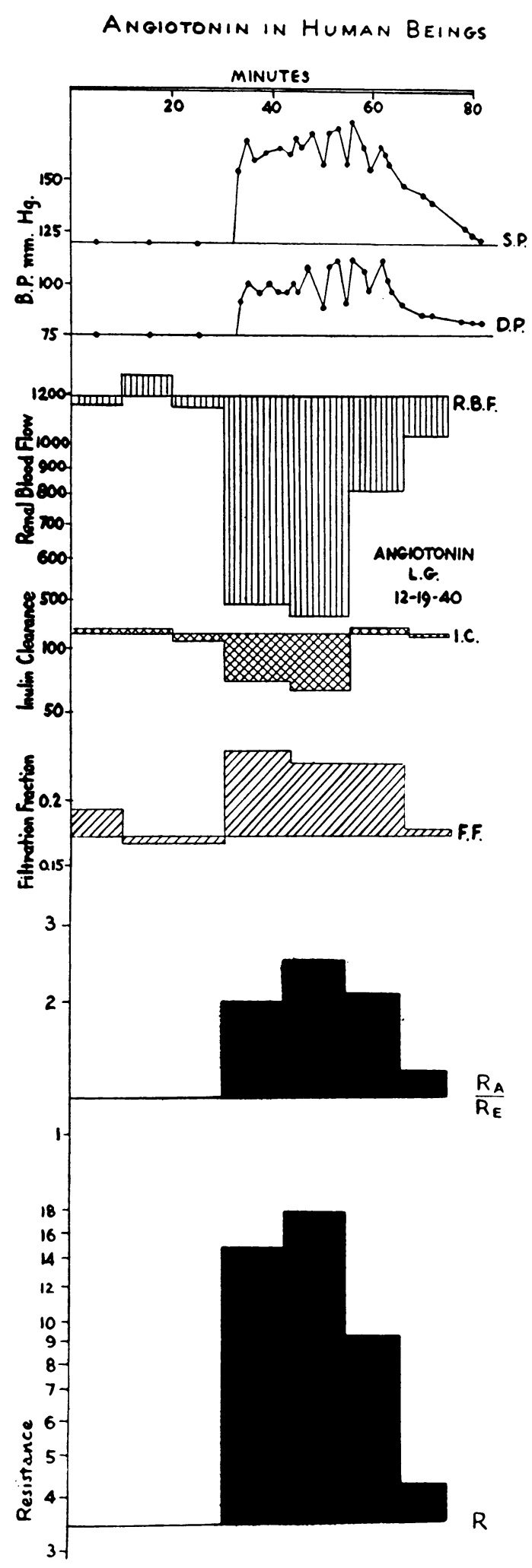

ance, $R$, and the afferent-to-efferent arteriolar ratio, $R_{A} / R_{E}$, are original. This case is of especial interest, partly because man is the subject, partly because it illustrates the value of a quantitative estimate of renal arteriolar resistance. Aside from the changes shown, which correspond to those in the dog, there was moderate increase in glomerular intra-capillary blood pressure. The rise in filtration fraction (FF) with the fall in blood flow (RBF) had been considered "the characteristic result of constriction of the glomerular efferent arterioles." It is seen, however, from $R_{A} / R_{E}$ that afferent arteriolar resistance increased proportionately more than efferent arteriolar resistance (Figure 1).

\section{Ratio of afferent to efferent arteriolar resistance in human hypertension}

The data in Table IV are calculated from those reported in essential hypertension by Goldring

TABLE IV

Afferent-to-efferent arteriolar ratio in essential hypertension

Mean
$\begin{gathered}\text { blood pressure } \\ \mathrm{mm} . \mathrm{Hg} .\end{gathered}$

$124 \ldots \ldots \ldots \ldots \ldots \ldots \ldots \ldots \ldots \ldots \ldots \ldots \ldots$

$122 \ldots \ldots \ldots \ldots \ldots \ldots \ldots \ldots$

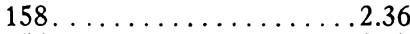

$156 \ldots \ldots \ldots \ldots \ldots \ldots .3 .67$

$152 \ldots \ldots \ldots \ldots \ldots 2.56$

$163 \ldots \ldots \ldots \ldots \ldots \ldots \ldots$

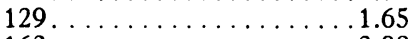

$162 \ldots \ldots \ldots \ldots \ldots \ldots \ldots 28$

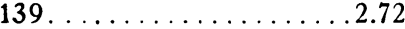

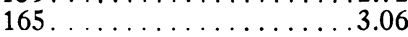

$160 \ldots \ldots \ldots \ldots \ldots \ldots 3.5 \ldots \ldots$

$195 \ldots \ldots \ldots \ldots \ldots \ldots \ldots \ldots+\ldots \ldots$

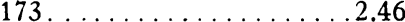

$122 \ldots \ldots \ldots \ldots \ldots \ldots 2.48$

$137 \ldots . .2 .58$

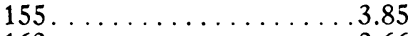

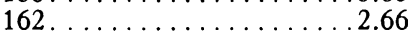

Average $\quad 151 \ldots \ldots \ldots \ldots \ldots 2 . \ldots \ldots 2$

Normal $\sigma^{\top} 100 \ldots \ldots \ldots \ldots \ldots \ldots \ldots 1 . \ldots \ldots$

Normal \& $100 \ldots \ldots \ldots \ldots \ldots \ldots . . \ldots 1.05$

et al. (9). They are drawn from the first 17 cases in their series, with mean blood pressure greater than $120 \mathrm{~mm}$. $\mathrm{Hg}$, averaging the sets of basal observations for each individual. In every case, the afferent-to-efferent arteriolar ratio is

Fig. 1. EFfect on Renal Function of Intravenous Angiotonin in MaN

Afferent arteriolar constriction exceeds efferent arteriolar constriction as shown by the increase in their ratio $\left(R_{A} / R_{E}\right)$. 
greater than the normal one for men or women if the normal blood pressure is taken at $100 \mathrm{~mm}$. $\mathrm{Hg}$. A predominance of afferent arteriolar constriction seems outstanding in essential hypertension.

\section{Renal function in late toxemia of pregnancy}

Corcoran and Page (7) found that "decreased filtration fraction, whatever the level of renal blood flow, is frequently associated with a severe course and with eclampsia." Table V comprises this group with low filtration fraction where measurements of diodrast clearance (cc. per 1.73 sq. m. per minute) were made. The serum protein was subnormal and variable in these cases so that a correction for the consequent changes in blood viscosity has been made as described elsewhere (2).

Aside from the fall in renal blood flow along with decline in blood pressure, and the rise in filtration fraction and serum protein during recovery, we are impressed with the apparently high initial degree of afferent arteriolar constriction. The afferent-to-efferent arteriolar ratio declined in all cases except the one (No. 8) which developed persistent hypertension (Table V).

\section{DISCUSSION}

It does not appear that the action of pitressin, renin, or angiotonin can, at present, be considered confined either to afferent or efferent arterioles. Conclusions based on dialectic reasoning are not adequate in deciding whether a given change in renal function is due to change predominantly in the afferent or efferent arterioles. Where so many factors are involved (blood pressure, blood flow, filtration fraction, hematocrit, osmotic pressure, viscosity), such reasoning can break down and a mathematical method for revealing related manifestations becomes essential.

Perhaps the most outstanding application of formulas for renal arteriolar resistance is to the question of the relative importance of efferent arteriolar constriction in human hypertension. Since renal blood flow is only slightly reduced while filtration fraction is slightly increased in hypertension $(9,10)$, an examination of the formula for $R_{E}$ shows that slight increase in efferent arteriolar resistance should be expected in the hypertensive The blood pressure $\left(P_{M}\right)$ does not even enter into the formula for $R_{E}$, but it appears so prominently in the one for $R_{A}$, that

TABLE v

Late loxemia of pregnancy

\begin{tabular}{|c|c|c|c|c|c|c|c|c|c|c|c|c|}
\hline $\begin{array}{l}\text { Case, } \\
\text { mild or } \\
\text { severe }\end{array}$ & $\begin{array}{c}\text { Days } \\
\text { ante- } \\
\text { or post- } \\
\text { partum }\end{array}$ & $\begin{array}{c}\text { Glomerular } \\
\text { filtration } \\
\text { rate } \\
I\end{array}$ & $\underset{H D}{\text { Blood flow }}$ & $\begin{array}{l}\text { Filtra- } \\
\text { tion } \\
\text { fraction } \\
F=I / D\end{array}$ & $\begin{array}{l}\text { Blood } \\
\text { pres- } \\
\text { sure } \\
\boldsymbol{P}_{\boldsymbol{M}}\end{array}$ & $\begin{array}{c}\text { Glomer- } \\
\text { ular } \\
\text { intra- } \\
\text { capillary } \\
\text { pressure } \\
P_{G}\end{array}$ & $\begin{array}{c}\text { Serum } \\
\text { pro- } \\
\text { tein } \\
S\end{array}$ & $\begin{array}{c}\text { Relative } \\
\text { blood } \\
\text { vis- } \\
\text { cosity } \\
U\end{array}$ & $\begin{array}{c}\text { Afferent } \\
\text { arteriolar } \\
\text { hydraulic } \\
\text { resistance } \\
\boldsymbol{R}_{\text {. }}\end{array}$ & $\begin{array}{c}\text { Efferent } \\
\text { arteriolar } \\
\text { hydraulic } \\
\text { resistance } \\
\boldsymbol{R}_{\bullet}\end{array}$ & $\begin{array}{c}\text { Total } \\
\text { arteriolar } \\
\text { hydraulic } \\
\text { resistance } \\
R_{r}\end{array}$ & $\begin{array}{c}\text { Afferent resistance } \\
\text { Efferent resistance } \\
R_{\bullet} / R_{\bullet}\end{array}$ \\
\hline & & $\begin{array}{l}\text { cc. per } \\
1.79 \text { square } \\
\text { meters per } \\
\text { minule }\end{array}$ & $\begin{array}{l}c c . \text { per } \\
1.73 \text { square } \\
\text { meters per } \\
\text { minute }\end{array}$ & per cent & $\operatorname{mm}_{\boldsymbol{B}}$ & $m m . H_{g}$ & $\begin{array}{l}\text { erams } \\
\text { per } \\
100 \mathrm{cc} .\end{array}$ & $\begin{array}{l}\text { referred } \\
\text { to water } \\
\text { as unity }\end{array}$ & \multicolumn{3}{|c|}{$\begin{array}{l}\text { mm. Hg per liter per } 1.75 \\
\text { square meters per minute } \\
\text { referred to water }\end{array}$} & \\
\hline $1 \mathrm{~S}$ & $\begin{array}{r}20 \mathrm{~A} \\
6 \mathrm{P} \\
72 \mathrm{P}\end{array}$ & $\begin{array}{r}82 \\
105 \\
92\end{array}$ & $\begin{array}{r}1050 \\
907 \\
675\end{array}$ & $\begin{array}{l}12.5 \\
20.0 \\
23.0\end{array}$ & $\begin{array}{l}155 \\
135 \\
120\end{array}$ & $\begin{array}{l}44.2 \\
47.9 \\
72.6\end{array}$ & $\begin{array}{l}5.8 \\
5.8 \\
7.8\end{array}$ & $\begin{array}{l}3.28 \\
3.54 \\
4.24\end{array}$ & $\begin{array}{c}26.3 \\
20.9 \\
9.57\end{array}$ & $\begin{array}{l}3.93 \\
5.11 \\
9.64\end{array}$ & $\begin{array}{l}30.2 \\
26.0 \\
19.2\end{array}$ & $\begin{array}{l}6.71 \\
4.08 \\
0.99\end{array}$ \\
\hline $4 \mathrm{~S}$ & $\begin{array}{r}18 \mathrm{~A} \\
5 \mathrm{P} \\
109 \mathrm{P}\end{array}$ & $\begin{array}{r}81 \\
93 \\
130\end{array}$ & $\begin{array}{r}1065 \\
705 \\
850\end{array}$ & $\begin{array}{l}12.1 \\
22.5 \\
23.8\end{array}$ & $\begin{array}{l}145 \\
125 \\
108\end{array}$ & $\begin{array}{l}35.6 \\
38.6 \\
82.2\end{array}$ & $\begin{array}{l}4.3 \\
4.3 \\
8.3\end{array}$ & $\begin{array}{l}3.82 \\
2.88 \\
4.13\end{array}$ & $\begin{array}{c}22.0 \\
32.8 \\
1.65\end{array}$ & $\begin{array}{l}2.88 \\
6.8 \\
9.34\end{array}$ & $\begin{array}{l}24.9 \\
39.6 \\
11.0\end{array}$ & $\begin{array}{l}7.64 \\
4.81 \\
0.176\end{array}$ \\
\hline $\begin{array}{l}\text { (2 mos. } \\
\text { preg.) }\end{array}$ & $\begin{array}{r}3 \mathrm{P} \\
16 \mathrm{P} \\
37 \mathrm{P} \\
114 \mathrm{P}\end{array}$ & $\begin{array}{r}68 \\
62 \\
79 \\
104\end{array}$ & $\begin{array}{r}1075 \\
436 \\
595 \\
985\end{array}$ & $\begin{array}{l}10.5 \\
23.0 \\
22.0 \\
17.0\end{array}$ & $\begin{array}{r}130 \\
100 \\
98 \\
\cdot 87\end{array}$ & $\begin{array}{l}45.3 \\
62.0 \\
61.0 \\
56.4\end{array}$ & $\begin{array}{l}6.1 \\
7.0 \\
7.0 \\
7.0\end{array}$ & $\begin{array}{l}3.53 \\
3.75 \\
3.80 \\
3.87\end{array}$ & $\begin{array}{c}17.1 \\
11.0 \\
75.2 \\
2.77\end{array}$ & $\begin{array}{c}3.51 \\
14.0 \\
-9.76 \\
4.84\end{array}$ & $\begin{array}{r}20.6 \\
25.0 \\
85.0 \\
7.6\end{array}$ & $\begin{array}{l}4.85 \\
0.785 \\
0.771 \\
0.573\end{array}$ \\
\hline $\begin{array}{r}8 \mathrm{M} \\
(\mathrm{HBP})\end{array}$ & $\begin{array}{r}6 \mathrm{P} \\
16 \mathrm{P} \\
64 \mathrm{P}\end{array}$ & $\begin{array}{l}92 \\
90 \\
98\end{array}$ & $\begin{array}{r}1105 \\
744 \\
765\end{array}$ & $\begin{array}{l}14.3 \\
19.8 \\
22.0\end{array}$ & $\begin{array}{l}160 \\
105 \\
128\end{array}$ & $\begin{array}{l}45.0 \\
46.3 \\
45.2\end{array}$ & $\begin{array}{l}5.8 \\
5.6 \\
5.3\end{array}$ & $\begin{array}{l}4.50 \\
3.28 \\
3.29\end{array}$ & $\begin{array}{l}24.6 \\
15.9 \\
25.0\end{array}$ & $\begin{array}{l}3.66 \\
6.50 \\
6.33\end{array}$ & $\begin{array}{l}28.3 \\
22.4 \\
31.3\end{array}$ & $\begin{array}{l}6.72 \\
2.44 \\
3.95\end{array}$ \\
\hline $12 \mathrm{~S}$ & $\begin{array}{r}3 \mathrm{~A} \\
12 \mathrm{P} \\
112 \mathrm{P}\end{array}$ & $\begin{array}{r}103 \\
99 \\
119\end{array}$ & $\begin{array}{r}1048 \\
805 \\
776\end{array}$ & $\begin{array}{l}15.8 \\
19.2 \\
24.9\end{array}$ & $\begin{array}{l}125 \\
103 \\
101\end{array}$ & $\begin{array}{l}49.5 \\
51.6 \\
68.1\end{array}$ & $\begin{array}{l}6.3 \\
6.3 \\
7.3\end{array}$ & $\begin{array}{l}3.50 \\
3.40 \\
3.90\end{array}$ & $\begin{array}{c}15.2 \\
11.5 \\
4.28\end{array}$ & $\begin{array}{l}4.32 \\
6.38 \\
8.68\end{array}$ & $\begin{array}{l}19.5 \\
17.9 \\
13.0\end{array}$ & $\begin{array}{l}3.51 \\
1.80 \\
0.493\end{array}$ \\
\hline
\end{tabular}


fractional changes in $P_{M}$ produce proportionately larger changes in $R_{A}$, the afferent arteriolar resistance. 4 Therefore, in hypertension, we should expect that $R_{A} / R_{E}$ would be greater than normal (about 1.1) with afferent arteriolar constriction predominating. All the essential hypertensives here reported had high $R_{A} / R_{B}$, and so did the hypertensives who suffered from late toxemia of pregnancy, even when we restrict ourselves to the post-partum observations with normal rather than low filtration fractions. Further confirmation of this view of the importance of the afferent arterioles during blood pressure change in maintaining renal homeostasis is given by the data on $R_{A} / R_{E}$ in the fall of blood pressure found in spinal anesthesia in man (1). There $R_{A} / R_{E}$ dropped with fall in blood pressure, indicating that the afferent arterioles had dilated, with decreasing pressure, more than the efferent arterioles, in order to sustain glomerular intracapillary pressure. Another example of the close connection between afferent arteriolar resistance and blood pressure is the series with atropine after pitressin. There, afferent constriction accompanied the rise in blood pressure which very likely was uncomplicated by any direct atropine effect on the kidney. Furthermore, in the anesthetized dog, it has been shown that kidney blood flow varies much less than blood flow in the hind limb when blood pressure is varied reflexly over a wide range $(11,12)$.

These divergent causes of abnormal blood pressure, with compensation by the afferent arterioles so as to maintain some measure of renal homeostasis, suggest that, if blood pressure rise were prevented during the infusion of renin and angiotonin, and if the purely physical effect of the elevation in pressure (as opposed to its pharmacological cause) in hypertension and toxemia could be abolished, we might discover a considerable measure of specificity in the site of action of the drugs and the disease agents.

The low filtration fraction in the severer cases of late toxemia of pregnancy is an interesting

\footnotetext{
4 Blood flow rate appears in the denominator of both $R_{\triangle}$ and $R_{E}$ which leaves their ratio unaffected. An increase in filtration fraction will increase $P_{o^{\prime}}$, which will by itself tend to increase $R_{E}$ and decrease $R_{A}$, but to a much lesser extent than the opposing influence of the large increase in $P_{M}$ in hypertension.
}

finding. An examination of all the data (7) indicates that the cause is sometimes, in whole or in part, increased renal blood flow and sometimes, in whole or in part, the cause is a reduced rate of glomerular filtration. A low glomerular intra-capillary pressure can explain these various combinations of causes. In view of the high blood pressure, it is clear (both theoretically, from the formulas, and from $R_{a} / R_{b}$ in Table V) that considerable afferent arteriolar constriction would be required.

Other possible explanations must also be explored. While they are not mutually exclusive, it is simpler to deal with them as though they were, remembering meanwhile that combinations are possible.

A simple explanation would be that inulin clearance ceases to be a measure of filtration rate in these toxemia cases $(13,14)$. If the glomerular membrane were affected (swelling?) so that inulin did not diffuse through as completely as water, its clearance would be less than the glomerular clearance of water. True filtration fraction would therefore be greater than our recorded one. The argument for the identity of inulin clearance and filtration rate rests, in part, on the equality of the clearance rates of certain hexitols with that of inulin (15). Wellen, Welsh, and Taylor, Jr. (14) have compared the simultaneous clearance of inulin with that of mannitol and sorbitol, of lower molecular weight, in 5 preeclamptic subjects and found them identical. Though diffusion of all the 3 sugars may be equally retarded by the diseased glomeruli, as compared to water, it does not seem especially likely in view of their differing molecular weights.

Let us now consider the possibility that harm to the glomerular membrane interferes with the establishment of osmotic equilibrium between glomerular filtrate and the blood leaving the glomerular capillaries (13). This is the same as saying that the diffusion of water through the glomerular capillaries is not completed, so far as osmotic equilibrium is concerned, before the blood leaves Bowman's capsule. Our formula assumes that such equilibrium exists. If it is not achieved, glomerular intra-capillary pressure is higher than we have supposed, and our afferentto-efferent ratio is larger than it should be. If this possibility were in truth the case, we should 
expect a differential diffusion rate, not only between the slowed down water and the heavier inulin, but between inulin and the lighter sugars, which we have seen is not so.

While such an argument is not conclusive, it is at least presumptive that inulin clearance is a correct measure of filtration rate and that osmotic equilibrium is achieved in the glomerulus in toxemia of pregnancy.

Another workable hypothesis is that certain glomeruli, among many fairly normal ones, were completely impermeable to all the sugars, while permitting smaller molecules and water to pass. In this case, inulin clearance for the kidney as a whole would be less than actual glomerular filtration rate. If the transition stage from free passage of water plus all the sugars to water alone were rapid, very few glomeruli would be in the condition of differential filtration of sugars when clearances are measured clinically, so that the precision of measurement of clearance required to detect these few transitional glomeruli would be unobtainable.

This last suggestion emphasizes the peculiar significance of the formulas. They are not measuring the resistance of any particular arteriole. They are really measuring the resistance of the arterioles supplying an ideal functional nephron, which replaces the average of the millions of nephrons of the kidney. Where there is wide discrepancy between the function of the many nephrons in the kidney, as in a diseased state, the vagaries which may attend the usual meaning of inulin and diodrast clearances (13) are accentuated, and the broad integrating effect of the formulas requires evaluation.

Corcoran and Page (7), in considering the problem of the low filtration fraction in toxemia, write: "The decrease of filtration of water from plasma in these cases was due either to hemodynamic intrarenal changes resulting in decreased intraglomerular pressure ... or to increased resistance of the filtering surface." They conclude, however, that their first alternative is untenable when renal blood flow is normal or subnormal and that only efferent arteriolar dilatation, and not afferent arteriolar constriction, is a possibility with increased renal flow. Consequently, preferring a single explanation as the more likely, and citing histological findings, and not having the then unpublished evidence of the equal clearance of the hexitols, they argue in favor of a swelling of the glomerular membrane, whereby the passage of filtrate is impeded.

Dill et al. (16) decide against the notion of decreased glomerular membrane permeability, perhaps because of the albumin in the urine of the pre-eclamptic. It seems, however, quite possible for a membrane to have reduced permeability except for rare holes through which samples of all of the fluid, held back elsewhere, would pour. A clogged filter paper with a single pin-hole would be such an example.

As has been seen (Table $\mathrm{V}$ and also above), we feel it is quite possible for hemodynamic changes alone, exclusive of a pathological glomerular membrane, to explain the low filtration fraction in toxemia of pregnancy. The various ways in which the pathological glomerulus can interfere with the methods used have been discussed. Of them, the most appealing is the one which postulates some glomeruli, functional so far as water is concerned, but impermeable to all the hexitols. Can the idea of homeostasis as applied to the kidney help in distinguishing the most likely of the available alternatives?

In general, it appears that the kidney, like other organs in the body, acts in accordance with the principle of homeostasis. Its reaction to change in blood pressure has already been discussed. Especially does glomerular filtration rate tend to remain constant (17). Blood flow, also, seems to be more constant than in other organs $(11,12)$. When a system in stable equilibrium is disturbed, a new equilibrium is reached, near the first, in a direction such as to annul as far as possible, but not completely, that disturbance. ${ }^{5}$ This is really the biological analogue of the principle of mobile equilibrium of Le Chatelier (18). If the reduction in filtration fraction in toxemia of pregnancy minimizes, so far as renal homeostasis is concerned, the effects of increased blood pressure or reduced serum protein found in this disease, we should be more inclined to discount a specific renal effect in toxemia of pregnancy with low filtration fraction, whether on the permeability of the glomerular membrane or on the afferent arterioles. The

- For example, acid added to a buffered solution shifts the hydrogen ion concentration slightly to the acid side. 
observations would be explicable as a secondary renal response to physical changes in the bloodits increased arterial pressure and decreased protein content.

If we first consider increased blood pressure alone, we see from the formulas that, if the arterioles stay fixed, blood flow will be considerably increased. Furthermore, glomerular intra-capillary pressure will rise, which means that filtration fraction must have risen, according to the formula. Consequently, if homeostasis is the principle controlling the kidney during increase in blood pressure, we should expect the arterioles of the kidney to change their lumen so as to prevent a large increase in filtration fraction, but a slight rise is to be anticipated. This is the opposite of what we actually find in toxemia of pregnancy.

If serum protein falls while blood pressure and the arterioles are fixed, blood osmotic pressure falls so that a larger fraction of plasma than usual will be filtered before osmotic equilibrium is reached between glomerular filtrate and glomerular intra-capillary blood. That is to say, the filtration fraction $(F)$ will rise. Equilibrium, then, if homeostasis is to occur in the face of hypoproteinemia, should also entail an increased filtration fraction. ${ }^{6}$

Thus, both the hypertension and the low blood protein in severe toxemia of pregnancy should lead to high rather than low filtration fraction, unless there is a specific renal effect of the toxemia. Since low rather than high filtration fraction has been found, we consider that a specific effect on the kidney is likely in toxemia of pregnancy, but we are not able to resolve the dilemma between a vascular cause-primarily afferent arteriolar constriction - and impairment of the glomerular membrane. It is not unlikely that both effects exist together. ${ }^{7}$

\section{SUMMARY}

Formulas for renal afferent and efferent arteriolar resistance have been applied to data in

\footnotetext{
- The isolated kidney of the dog illustrates this, if it is comparable to the human kidney (19).

7 The increase in renal blood flow in the severe cases may well be, in part, a homeostatic mechanism to preserve adequate glomerular filtration rate in the face of a sluggish capillary filter.
}

the literature. It appears that dialectic reasoning concerning the predominance of afferent or efferent arteriolar constriction frequently leads to incorrect conclusions. Renal homeostasis and the importance of the afferent arterioles in protecting the kidney from blood pressure changes are discussed. The implications of the low filtration fraction observed in late toxemia of pregnancy are weighed.

\section{CONCLUSIONS}

1. Pitressin caused no consistent change in glomerular intra-capillary pressure, total effective renal arteriolar resistance, or in the afferent-toefferent arteriolar resistance ratio in unanesthetized dogs.

2. Atropine added to pitressin increased total effective arteriolar renal resistance, with afferent arteriolar constriction predominating, in unanesthetized dogs.

3. Renin infused into unanesthetized dogs increased glomerular intra-capillary pressure and total arteriolar resistance with neither afferent nor efferent constriction predominating consistently.

4. Angiotonin acted rather similarly to renin, but conclusions concerning it are subject to some doubt.

5. In one test on a human subject, angiotonin caused constriction of both sets of arterioles with afferent constriction predominating.

6. Afferent arteriolar constriction outweighed efferent constriction more than is normal in all of the 17 cases of essential hypertension studied.

7. It is likely that the resistance of the afferent arterioles varies with blood pressure changes so as to preserve renal function.

8. A specific renal effect is the probable cause of the low filtration fraction seen in late severe toxemia of pregnancy. There is inadequate evidence to decide how much of this effect is primarily constriction of the efferent arterioles and how much, if any, is change in the permeability of the glomerular membrane to water and/or inulin and other sugars.

\section{BIBLIOGRAPHY}

1. Lamport, H., Formulae for afferent and efferent arteriolar resistance in the human kidney: an application 
to the effects of spinal anesthesia. J. Clin. Invest. 1941, 20, 535.

2. Lamport H., To be published.

3. Corcoran, A. C., and Page, I. H., Effects of renin, pitressin, and pitressin and atropine on renal blood flow and clearance. Am. J. Physiol., 1939, 126, 354.

4. Corcoran, A. C., and Page, I. H., Effects of angiotonin on renal blood flow and glomerular filtration. Am. J. Physiol., 1940, 130, 335.

5. Corcoran, A. C., Kohlstaedt, K. G., and Page, I. H., Changes of arterial blood pressure and renal hemodynamics by injection of angiotonin in human beings. Proc. Soc. Exper. Biol. and Med., 1941, 46, 244.

6. Corcoran, A. C., and Page, I. H., Renal blood flow and sympathectomy in hypertension. Arch. Surg., 1941, 42, 1072.

7. Corcoran, A. C., and Page, I. H., Renal function in late toxemia of pregnancy. Am. J. M. Sc., 1941, 201, 385.

8. Adair, G. S., Adair, M. E., and Greaves, R. I. N., Osmotic pressure, after re-solution, of serum, dried from frozen state (F. D. serum). J. Hyg., 1940, 40, 548.

9. Goldring, W., Chasis, H., Ranges, H. A., and Smith, H. W., Effective renal blood flow in subjects with essential hypertension. J. Clin. Invest., 1941, 20, 637.

10. Smith, H. W., Studies in the physiology of the kidney. Porter Lecture Ser., No. 9, Lawrence, 1939.

11. Hartmann, H., Ørskov, S. L., and Rein, H., Die Gefässreaktionen der Niere im Verlaufe allgemeiner
Kreislauf-Regulationsvorgänge. Arch. f. d. ges. Physiol., 1936, 238, 239.

12. Opitz, E., and Smyth, D. H., Nierendurchblutung bei Reizung des Carotis-Sinus. Arch. f. d. ges. Physiol. 1937, 238, 633.

13. Smith, H. W., Note on interpretation of clearance methods in diseased kidney. J. Clin. Invest., 1941, 20, 631.

14. Wellen, I., Welsh, C. A., and Taylor, H. C., Jr., The filtration rate, effective renal blood flow, tubular excretory mass and phenol red clearance in specific toxemia of pregnancy. J. Clin. Invest., 1942, 21, 63.

15. Smith, W. W., Finkelstein, N., and Smith, H. W., Renal excretion of hexitols (sorbitol, mannitol, and dulcitol) and their derivatives (sorbiton, isomannide, and sorbide) and of endogenous creatine-like chromogen in dog and man. J. Biol. Chem., 1940, 135, 231.

16. Dill, L. V., Isenhour, M. A., Cadden, J. F., and Schaffer, N. K., Glomerular filtration and renal blood flow in the toxemias of pregnancy. Am. J. Obs. and Gyn., 1942, 43, 32.

17. Smith, H. W., and others, Glomerular dynamics in normal human kidney. J. Clin. Invest., 1940, 19, 751.

18. Glasstone, S., Text-Book of Physical Chemistry, New York, 1941.

19. Eggleton, M. G., Pappenheimer, J. R., and Winton, F. R., Mechanisms of dilution diuresis in isolated kidney and anesthetized dog. J. Physiol., 1940, 98, 336. 